\title{
Anaplasma ovis infection in goat flocks around Gaborone, Botswana
}

\author{
Jessica Berthelsson ${ }^{1} \cdot$ Solomon Stephen Ramabu ${ }^{2} \cdot$ Sara Lysholm $^{1} \cdot$ Anna Aspán ${ }^{1,3}$ • Jonas Johansson Wensman ${ }^{1}$ (i)
}

Received: 14 February 2019 / Accepted: 5 August 2019/Published online: 13 August 2019

(C) The Author(s) 2019

\begin{abstract}
Anaplasma is a genus of gram-negative, intracellular bacteria infecting different blood cells in animals. A. ovis infects erythrocytes of sheep and goats, inducing clinical signs that include haemolytic anaemia, icterus and loss of production. Aim of this study was to evaluate the prevalence of Anaplasma spp. in goats in smallholder flocks around Gaborone, Botswana. Whole blood and serum samples were collected from 100 goats coming from 10 smallholder goat flocks from three villages around Gaborone, Botswana. Body condition and FAMACHAC scores were estimated. Blood was used for packed cell volume (PCV), blood smears, PCR, including species-specific PCR assays for A. marginale and A. ovis, and serum samples were analysed by Anaplasma spp. cELISA. Each farmer was interviewed about management, health and treatment of the goats. Microscopic examination of Giemsa-stained blood smears showed inclusion bodies in 53\% of the samples. A seroprevalence of $88 \%$ was found on cELISA and 76\% of the goats were positive by PCR using general primers for Anaplasma spp. All PCR positive goats were infected with A. ovis and no goats were positive for A. marginale. Positive animals were found in all areas and in all flocks. There was no correlation between infection and clinical signs. In Botswana, A. ovis in goats does not seem to pose a significant problem even though the pathogen is endemic in the goat population, or perhaps, because of being endemic, herd immunity leads to less severe clinical signs.
\end{abstract}

Keywords Anaplasma $\cdot$ Small ruminants $\cdot$ Tick-borne disease $\cdot$ Epidemiology $\cdot$ Southern Africa

\section{Introduction}

Anaplasma is a genus of obligate intracellular, gram-negative bacteria that infect blood cells of mammals. These bacteria can cause diseases in vertebrates and the vertebrates may also serve as reservoirs (Rymaszewska and Grenda 2008). The Anaplasma species that infect and may cause disease in animals are A. marginale, A. ovis, A. centrale, A. bovis, A. phagocytophilum and A. platys, of which A. marginale, A. centrale and $A$. ovis are intra-erythrocytic and infect ruminants (Liu et al. 2012). In many tropical and subtropical areas worldwide, anaplasmosis is endemic and characterised by haemolytic anaemia (Fry and McGavin 2012).

Jonas Johansson Wensman

jonas.wensman@slu.se

1 Department of Clinical Sciences, Swedish University of Agricultural Sciences, P.O. Box 7054, SE-750 07 Uppsala, Sweden

2 Botswana University of Agriculture and Natural Resources, Private Bag 0027, Gaborone, Botswana

3 National Veterinary Institute, SE-751 89 Uppsala, Sweden
The transmission of the bacteria is mostly through tick vectors. The most important genera of ticks that transmit Anaplasma spp. are Ixodes, Dermacentor, Rhipicephalus and Amblyomma (Rymaszewska and Grenda 2008), of which Rhipicephalus and Amblyomma have been found on goats in Botswana (Mushi et al. 1996). Rhipicephalus evertsi is the tick species considered to transmit Anaplasma spp. to goats in the area of this study (Mushi et al. 1996).

Anaplasma ovis infection in goats can cause acute anaplasmosis with intra-erythrocytic inclusion bodies and severe anaemia (Ndung'u et al. 1995). Goats can remain mildly to moderately anaemic after the acute disease stage, when no inclusion bodies in the erythrocytes are detectable, most likely decreasing milk and meat production (Ndung'u et al. 1995). Often the microorganism only causes mild clinical signs, but it has been reported to cause more severe disease in goats due to stress factors such as co-infection or hot and dry climate (Renneker et al. 2013). Co-infection with other tick-borne diseases is an important factor to consider when evaluating the impact of Anaplasma spp. in animals (Renneker et al. 2013) and more severe clinical signs could be due to Anaplasma spp. having an impact on the immune system. 
Botswana is a landlocked country located in the southern part of Africa. It is now classified as an upper middle-income country after being one of the poorest countries in Africa before its independence in 1966 (World Bank 2016). Because of a dry climate and limited access to arable land, keeping cattle is the most important part of agriculture in Botswana. Not all farmers can afford cattle, because it is a relatively expensive investment and therefore a lot of farmers instead keep goats that are cheaper to purchase (Panin 2000). Goat herding is a significant part of the economy for smallholders in Botswana as a part of their income is based on selling the goats and goat kids (Panin and Mahabile 1997), and an outbreak of disease can thus be devastating to the owner.

The aim of this study was to evaluate the prevalence of Anaplasma spp. in goats in smallholder flocks around Gaborone in Botswana. Information about the goats' health status can contribute to the owners' awareness of the disease which can impact the way they manage their goats, especially with regard to tick control.

\section{Materials and methods}

\section{Study design, sample collection and clinical signs}

Blood samples from 100 goats were collected in three different villages, Modipane, Kopong and Gakuto, around Gaborone, Botswana, during September 2016, at the end of the dry season. The goat owners were smallholders and chosen depending on the village they lived in, keeping an appropriate number of adult goats, i.e. 20-30 goats which is the average herd size, and if they were willing to participate. Ten goats were sampled from each flock and all goat owners gave their permission to sample their goats.

Only goats more than 1 year old were sampled, including both males and females. Systematic random sampling was used in the following way; goats available for sampling were counted and then divided by ten to get the frequency of goats to sample. If the flock consisted of 30 adult animals, every third animal was sampled but all the animals were caught. In that way, both easy and difficult animals were caught.

All animals sampled were subjected to FAMACHA@ $\odot$ reading of the mucous membrane and a body condition score (BCS) estimation (Kaplan et al. 2004). This was carried out by the same person for all animals to minimise the risk for subjective differences between the groups. Blood samples were collected sterile with a vacutainer system (BD Biosciences, NJ, USA) from the jugular vein for collection of serum and blood anti-coagulated with $\mathrm{K}_{3}$-ethylenediaminetetraacetic acid (EDTA). The GPS coordinates of the kraal (pen) were noted.

\section{Interviews}

After the sampling, a short semi-structured interview was conducted with the goat owner and other people, often family members, taking care of the goats. One of the flocks was coowned and therefore 11 interviews were carried out. The questions were asked in English but in most cases needed to be translated into Setswana, the national language of Botswana. The translation was done by employees from the Botswana University of Agriculture and Natural Resources who also assisted with the sampling. Answers from the owners were noted and the interview took between 10 and $20 \mathrm{~min}$. The questions covered herd size, grazing system, biosecurity measures, animal health, prophylactic treatment strategies and socioeconomic impact of disease.

\section{Treatment of the blood samples}

Whole blood was used for preparing thin blood smears that later were stained with Giemsa and examined for inclusion bodies. The blood was also used to determine packed cell volume (PCV) using micro-haematocrit tubes that were centrifuged for $5 \mathrm{~min}$ at $12000 \mathrm{rpm}$ and read with a microhaematocrit reader. Whole blood was then frozen at $-20{ }^{\circ} \mathrm{C}$ until used for DNA extraction. Blood without anti-coagulant was left to coagulate and serum was separated from the coagulate and frozen at $-20{ }^{\circ} \mathrm{C}$ until further used for ELISA.

\section{Diagnostic tests}

\section{Blood smears}

Blood smears were stained with Giemsa and examined under a microscope with $\times 100$ magnification (Leica DM500, Leica Microsystems, Switzerland). Each slide was examined for 5 min and samples with one or more inclusion bodies were classified as positive.

\section{cELISA}

Sera were used in a competitive, enzyme-linked, immunosorbent assay (cELISA) for detection of antibodies to Anaplasma spp. The cELISA was carried out according to the instructions from the manufacturer (Veterinary Medical Research and Development, Pullman, USA) using $50 \mu$ l of each serum sample. The plate was then read in a microplate absorbance spectrophotometer (Multiskan FC, Thermo Scientific, Waltham, USA) at a wavelength of $620 \mathrm{~nm}$. The percentage of inhibition was calculated and samples with an inhibition of $\geq 30 \%$ were considered positive, while samples with an inhibition of $<$ $30 \%$ were considered negative. 


\section{DNA extraction}

DNA was extracted from $50 \mu$ l of whole blood using DNeasy Blood and Tissue kit according to the manufacturer's instructions (Qiagen, Poland). The extracted DNA was stored in $20{ }^{\circ} \mathrm{C}$ until used.

\section{PCR}

Extracted DNA from all samples was subsequently used in a PCR assay for detection of Anaplasma spp. Five microliter of DNA were mixed with $12.5 \mu$ l of AmpliTaq Gold 360 Master Mix (Applied Biosystems, Life technologies, California, USA), $0.4 \mu \mathrm{M}$ of forward and reverse primer, respectively, in a total volume of $25 \mu \mathrm{l}$. Primers for general Anaplasma spp. detection were used; MSP45: 5'-GGGA GCTCCTATGAATTACAGAGAATTGTTTAC-3' and MSP43: 5'-CCGGATCCTTAGCTGAACAGGAATCT TGC-3' (de la Fuente et al. 2007). The following conditions were used for the thermocycler (2720 Thermal Cycler, Applied Biosystems, Waltham, USA): initial denaturation at $95^{\circ} \mathrm{C}$ for $10 \mathrm{~min}, 35$ cycles of denaturation at $95^{\circ} \mathrm{C}$ for $30 \mathrm{~s}$, annealing at $53{ }^{\circ} \mathrm{C}$ for $30 \mathrm{~s}$ and extension at $72{ }^{\circ} \mathrm{C}$ for $60 \mathrm{~s}$, followed by a final extension at $72{ }^{\circ} \mathrm{C}$ for $7 \mathrm{~min}$. PCR products were analysed by gel electrophoresis in a $1 \%$ agarose gel with a 50-base pair ladder and visualised under UV light. Expected length of the PCR product was around 850 base pairs.

Samples positive for Anaplasma spp. in the general MSP4PCR were further analysed in specific PCR assays for $A$. marginale and A. ovis. For A. marginale, msp $1 \mathrm{~b}$ primer An_ma_msp1_F: 5'-CAGGCTTCAAGCGTACAGTG-3' and An_ma_msp1_R: 5'-GATATCTGTGCCTGGCCTTC-3' were used (Michelet et al. 2014). For A. ovis, MSP4 primer An_ov_msp4_F: 5'-TCATTCGACATGCGTGAGTCA-3' and An_ov_msp4_R: 5'-TTTGCTGGCGCACTCACATC-3' were used (Michelet et al. 2014). The following thermoprofile was used: initial denaturation at $95{ }^{\circ} \mathrm{C}$ for $10 \mathrm{~min}$, 35 cycles of denaturation at $95{ }^{\circ} \mathrm{C}$ for $30 \mathrm{~s}$, annealing at $53{ }^{\circ} \mathrm{C}$ for $30 \mathrm{~s}$ and extension at $72{ }^{\circ} \mathrm{C}$ for $60 \mathrm{~s}$, followed by a final extension at $72{ }^{\circ} \mathrm{C}$ for $7 \mathrm{~min}$. PCR products were analysed by gel electrophoresis in a $2 \%$ agarose gel with a 50-base pair ladder and visualised under UV light. No positive control was used for this step due to lack of assured positive samples for A. ovis and A. marginale. The A. marginale and $A$. ovis products were expected to be 85 and 92 base pairs, respectively.

\section{Extraction from FTA cards and DNA sequencing}

The remaining PCR products from each sample were transferred to Whatman FTA cards (Sigma-Aldrich, Saint-Louis, MO, USA) to enable transport. Later, cards from one positive animal from each flock were selected for further processing. A 2-mm punch was obtained using a Harris micropunch (GE Healthcare, Uppsala, Sweden) and the applied PCR material was eluted according to the instructions provided by the manufacturer (Sigma-Aldrich, St. Louis, USA). After this, PCR was performed on the eluted material. The reaction volume was $25 \mu \mathrm{l}$, containing $12.5 \mu \mathrm{l} 2$ xPCRBIO Ultra Mix (PCR BIOSYSTEMS, London, UK), $5 \mu$ sample material or nuclease-free water for the negative control and $0.4 \mu \mathrm{M}$ of the general Anaplasma spp. primers MSP43 and MSP45 (de la Fuente et al. 2007). The following conditions were used for the thermocycler (ProFlex PCR System, Applied Biosystems, Foster City, California, USA): $95^{\circ} \mathrm{C}$ for $2 \mathrm{~min}$, followed by 35 cycles of $95^{\circ} \mathrm{C}$ for $15 \mathrm{~s}, 55^{\circ} \mathrm{C}$ for $15 \mathrm{~s}$ and $72{ }^{\circ} \mathrm{C}$ for $15 \mathrm{~s}$. Generated PCR products were purified using a GeneJET Gel Extraction Kit (Thermo Scientific, Foster City, California, USA) and prepared for Sanger sequencing. In total, eight samples of extracted DNA deriving from 6 different animals were sent for sequencing. Each village was represented by at least one goat. Samples were then sent to Macrogen (Amsterdam, the Netherlands) for sequencing. The sequences were analysed and interpreted using CLC Main Workbench 7 software (QIAGEN Bioinformatics, Aarhus, Denmark).

\section{Statistical analysis}

Data gathered from sampling and diagnostic tests were compiled in a MicroSoft Excel sheet. All statistical analysis was performed in Minitab 17 Statistical Software. For the proportions, confidence intervals of $95 \%$ were calculated. Differences between the villages' results were calculated through ANOVA (analysis of variance) and Spearman's rank correlation coefficient was used to calculate correlation.

\section{Results}

\section{Interviews}

In total, interviews of 11 goat farmers were carried out, one for each flock. Goat owners kept between 9 and 70 adult goats with a mean flock size around 30 adults. The exact number could not be calculated since all owners did not know or did not want to reveal how many animals they kept. The goat owners had between 0 and 30 kids. A majority of the owners kept other ruminants like cattle or sheep and most of them grazed together with, or in the same area, as the goats. All owners reported that their goats stayed in the kraal (pen) at night and grazed freely on communal grazing areas during the day. The owners stated that their goats mixed with goats from other herds during grazing.

All owners from Modipane reported seeing wild ruminants in the same areas where their goats grazed. In Kopong and Gakuto, one out of three owners reported seeing wild 
ruminants, but did not mention as many species as the owners in Modipane. Species that had been observed were among others; kudu, impala, duiker and springbok.

The owners had different opinions about the health of their animals. Some thought they were in good condition while some thought the animals had some health problems. When asked about specific clinical signs most owners had experienced abortion and diarrhoea. Some owners never treated their animals with medications, while others did deworming and occasionally treated sick animals with antibiotics. Most owners did not vaccinate their goats. All owners had treated their animals at least once with drugs against ticks through dipping. Most of them stated that they treated the goats when they considered the ticks to be a problem instead of doing it regularly.

Mostly, goat owners acquired new animals by raising the kids born in their own flock, but two of them said they also occasionally bought from other farmers in the village or from nearby villages. All goat owners stated that it would greatly affect them in a negative way if the majority of their animals got sick and died. Most of the owners make their living from selling live goats so they would primarily be affected economically. Some also stated that it would be difficult emotionally since the goats are important to them, and some owners even used the word devastating.

\section{Body condition score, FAMACHA® score and packed cell volume}

The mean BCS, FAMACHA and PCV for all groups were 3.3, 2.4 and $33.0 \%$, respectively. Mean values for the different villages are shown in Table 1. Significant differences between the villages BSC $(p$ value $=0.05)$, FAMACHA $\odot(p$ value $=$ $0.02)$ and PCV ( $p$ value $<0.0005)$ were found. None of the goats were anaemic according to PCV, but 9 out of 100 goats had a FAMACHAC score of 4 , undoubtedly classified as anaemic.

\section{Diagnostic tests}

Microscopic examination of Giemsa-stained blood smears determined that $53 \%$ of the goats were positive with one or more inclusion bodies detected in the erythrocytes. The highest prevalence of animals with erythrocytic inclusion bodies was seen in Modipane (Table 2). Overall, $88 \%$ of the goats were seropositive for Anaplasma spp. as determined by cELISA. The number of goats PCR-positive using MSP4 primers was $76 / 100(76 \%)$. A $p$ value of 0.22 indicates that no statistically significant difference in prevalence could be found when comparing the PCR results from the different villages through ANOVA.

\section{Anaplasma species-specific PCR assays and sequencing}

Samples positive for Anaplasma spp. $(n=76)$ were analysed in specific PCR assays for A. ovis and A. marginale. All samples tested negative for $A$. marginale, while all were positive for A. ovis; however, species-specific positive controls were not available. To confirm the species of Anaplasma present in the goats, the general Anaplasma spp. PCR assay was repeated, using samples from FTA cards representing at least one PCR-positive goat in each herd. Due to low concentrates of template, only two samples were sequenced successfully, and three samples gave partial sequencing results, i.e. only short stretches of high-quality sequences were obtained for these samples. Samples derived from five different animals and each village was represented by at least one goat. The sequences from two animals (animals M2-2 and K1-5) matched $100 \%$ (796 out of 796 bases blasted) with sequences in GenBank (Accession date 16-01-2019) for A. ovis. Sequences reads obtained from the other three samples were shorter and also matched with A. ovis only (animals K2-3, K3-1 and G3-7), with $100 \%$ scores for 440,440 and 201 nucleotides blasted, respectively.

\section{Correlation between clinical signs and presence of $A$. ovis}

A weak negative correlation between PCV and FAMACHAC was found (Spearman's rank correlation coefficient $-0.52 ; p$ value $<0.0005)$, i.e. a higher FAMACHA® score was correlated with a lower PCV. Even though a correlation was found, none of the goats classified as anaemic on the FAMACHAC
Table 1 Mean values of BCS, FAMACHA® and PCV for the different villages

\begin{tabular}{llll}
\hline & $\begin{array}{l}\text { Body condition score } \\
\text { (optimal 2-3) }\end{array}$ & $\begin{array}{l}\text { FAMACHAC } \\
\text { (normal 1-2) }\end{array}$ & PCV in \% (95\% CI) \\
\hline All villages $(n=100)$ & 3.3 & 2.4 & $33.0(32.0,34.1)$ \\
Modipane $(n=40)$ & 3.1 & 2.2 & $34.2(32.8,35.6)$ \\
Kopong $(n=30)$ & 3.4 & 2.7 & $29.6(28.1,31.2)$ \\
Gakuto $(n=30)$ & 3.4 & 2.3 & $34.9(32.9,36.9)$ \\
\hline
\end{tabular}

${ }^{1}$ Normal PCV range in goats 22-38\% (Fielder 2016) 
Table 2 Number and proportion of Anaplasma spp. positives for each village and diagnostic method

\begin{tabular}{|c|c|c|c|c|c|c|}
\hline & \multicolumn{2}{|c|}{ Blood smears } & \multicolumn{2}{|c|}{ cELISA } & \multirow[b]{2}{*}{$n$} & \multirow{2}{*}{$\begin{array}{l}\text { PCR } \\
\text { Prevalence }(95 \% \mathrm{CI})\end{array}$} \\
\hline & $n$ & Prevalence $(95 \% \mathrm{CI})$ & $n$ & Prevalence $(95 \% \mathrm{CI})$ & & \\
\hline Modipane $(n=40)$ & 31 & $78 \%(61.5,89.2)$ & 40 & $100 \%(91.2,100)$ & 35 & $88 \%(73.2,95.8)$ \\
\hline M1 $(n=10)$ & 10 & $100 \%$ & 10 & $100 \%$ & 9 & $90 \%$ \\
\hline M2 $(n=10)$ & 8 & $80 \%$ & 10 & $100 \%$ & 10 & $100 \%$ \\
\hline M3 $(n=10)$ & 8 & $80 \%$ & 10 & $100 \%$ & 9 & $90 \%$ \\
\hline M4 $(n=10)$ & 5 & $50 \%$ & 10 & $100 \%$ & 7 & $70 \%$ \\
\hline Kopong $(n=30)$ & 15 & $50 \%(31.3,68.7)$ & 28 & $93 \%(77.9,99.2)$ & 24 & $80 \%(61.4,92.3)$ \\
\hline $\mathrm{K} 1(n=10)$ & 5 & $50 \%$ & 10 & $100 \%$ & 6 & $60 \%$ \\
\hline $\mathrm{K} 2(n=10)$ & 7 & $70 \%$ & 9 & $90 \%$ & 10 & $100 \%$ \\
\hline $\mathrm{K} 3(n=10)$ & 3 & $30 \%$ & 9 & $90 \%$ & 8 & $80 \%$ \\
\hline Gakuto $(n=30)$ & 7 & $23 \%(9.9,42.3)$ & 20 & $67 \%(47.2,82.7)$ & 17 & $57 \%(37.4,74.5)$ \\
\hline $\mathrm{G} 1(n=10)$ & 2 & $20 \%$ & 4 & $40 \%$ & 5 & $50 \%$ \\
\hline $\mathrm{G} 2(n=10)$ & 1 & $10 \%$ & 9 & $90 \%$ & 9 & $90 \%$ \\
\hline G3 $(n=10)$ & 4 & $40 \%$ & 7 & $70 \%$ & 3 & $30 \%$ \\
\hline
\end{tabular}

CI, confidence interval. M1-M4: sampled flocks in Modipane. K1-K3: sampled flocks in Kopong. G1-G3: sampled flocks in Gakuto score were anaemic according to PCV. There was a weak correlation between higher FAMACHA@ score and a positive PCR result (Spearman's rank correlation coefficient $0.35 ; p$ value $<0.0005$ ). Lower BCS was not correlated with a positive PCR result (Spearman's rank correlation coefficient $0.31 ; p$ value $=0.002$ )

\section{Discussion}

The prevalence of Anaplasma spp. (A. ovis) was $76 \%$ according to PCR, which is consistent with other studies conducted on goats in Africa (Kubelova et al. 2012; Ndung'u et al. 1995; Shompole et al. 1989). From microscopic examination of Giemsa-stained blood smears, only $53 \%$ of the animals had inclusion bodies and this difference in prevalence is in accordance with another study that has shown PCR to have a higher sensitivity than microscopy in detection of Anaplasma species (Jalali et al. 2013). PCR with the specific primers showed that none of the goats carried $A$. marginale, but all were positive for $A$. ovis. This result was further confirmed by sequencing. A. marginale usually infects cattle even though it has been found in goats previously (Shompole et al. 1989). The overall seroprevalence for Anaplasma spp. in this study was $88 \%$, similar to previous findings in cattle in the same area (Ramabu et al. 2018).

Some animals had inclusion bodies in the erythrocytes, but were PCR negative. This discrepancy could be due to misinterpretation of the inclusion bodies in the light microscope. An inclusion body can resemble both Howell-Jolly bodies, other intra-erythrocytic parasites and staining artefacts. Some animals were PCR positive, but ELISA negative (data not shown), which can be due to a weak immune response or that the goat has been recently infected and not yet seroconverted. Other animals were ELISA positive, but PCR negative (data not shown), which suggests that after the acute phase some persistently infected goats are below PCR detection. This might not be the case for goats in the same extent as for cattle since $A$. ovis seems less prone to cause clinical disease in goats than $A$. marginale in cattle.

None of the goats were perceived to be unhealthy during the sampling according to the owners. The goats were mostly kept for selling and there were no production records. However, none of the owners reported a loss in production. Nevertheless, there could have been a loss in production but this would have to be examined closer. Some of the owners gave their goats water once a day while others had unlimited access to water. Either way the mean PCV of the sampled goats $(33.0 \%)$ in this study was higher than previously reported $(24.5 \%$ and $25.1 \%$ ) for healthy goats in Botswana (Adogla-Bessa and Aganga 2000). This could be because the sampling occurred during the dry season or that the goats might not be able to drink enough even if they have been offered water. The normal PCV range for goats is $22-38 \%$ (Fielder 2016), and most of the goats were within this range. Some goats had higher PCV, most likely due to dehydration. None of the goats were anaemic according to PCV.

A high FAMACHA@ score (>3) was weakly correlated to a positive PCR for Anaplasma spp. However, the goats did not show any clinical signs even when they were infected. There was a correlation between FAMACHAC and PCV, as expected, since FAMACHAC is a method of evaluating if the animal has anaemia.

In Botswana, A. ovis in goats does not seem to pose a significant problem even though the pathogen is endemic in 
the goat population, or perhaps, because of being endemic, herd immunity leads to less severe clinical signs. For some individual animals with a suppressed immune system, A. ovis could cause clinical disease, but mostly it is a subclinical infection in goats. No correlation between A. ovis infection and PCV could be found and this is probably due to the infection being in the persistent phase of disease or the disease being subclinical.

Acknowledgements We would like to thank all the goat owners who participated for letting us sample their goats and answering our questions.

Funding information Open access funding provided by Swedish University of Agricultural Sciences. This project was supported by a scholarship for a Minor Field Study funded by the Swedish International Development Cooperation Agency (Sida) and financial support from the Swedish Research Council (Grant no. 348-2014-4293 and 2016-05667). Additional scholarships were granted from Elsa Paulsson memorial fund (Stiftelsen Elsa Paulssons minnesfond) and the Student Union of Veterinary Medicine in Sweden (Internationella utskottet, Veterinärmedicinska föreningen).

\section{Compliance with ethical standards}

Statement of animal rights Handling of animals during the performance of this study met the terms of the International guiding principles for biomedical research involving animals. The study was under the auspices of the Animal Care and Use Committee (ACUC) of the University of Botswana.

Conflict of interest The authors declare that they have no conflict of interest.

Open Access This article is distributed under the terms of the Creative Commons Attribution 4.0 International License (http:// creativecommons.org/licenses/by/4.0/), which permits unrestricted use, distribution, and reproduction in any medium, provided you give appropriate credit to the original author(s) and the source, provide a link to the Creative Commons license, and indicate if changes were made.

\section{References}

Adogla-Bessa T, Aganga AA (2000) Responses of Tswana goats to various lengths of water deprivation S Afr. J Anim Sci 30:87-91

de la Fuente J, Atkinson MW, Naranjo V, Fernandez de Mera IG, Mangold AJ, Keating KA, Kocan KM (2007) Sequence analysis of the msp4 gene of Anaplasma ovis strains. Vet Microbiol 119: 375-381. https://doi.org/10.1016/j.vetmic.2006.09.011

Fielder SE (2016) Hematologic reference ranges. Merck. http://www. merckvetmanual.com/appendixes/reference-guides/hematologicreference-ranges. Accessed 7th Jan 2017

Fry MM, McGavin MD (2012) Bone marrow, blood cells and the lymphatic system. In: Zachary JF, McGavin MD (eds) Pathologic basis of veterinary disease. 5 edn. Elsevier Mosby, St. Louis, p 720
Jalali SM, Khaki Z, Kazemi B, Bandehpour M, Rahbari S, Jalali MR, Yasini SP (2013) Molecular detection and identification of Anaplasma species in sheep from Ahvaz, Iran. Iran J Vet Res 14: $50-56$

Kaplan RM, Burke JM, Terrill TH, Miller JE, Getz WR, Mobini S, Valencia E, Williams MJ, Williamson LH, Larsen M, Vatta AF (2004) Validation of the FAMACHA eye color chart for detecting clinical anemia in sheep and goats on farms in the southern United States. Vet Parasitol 123:105-120. https://doi.org/10.1016/j.vetpar. 2004.06.005

Kubelova M, Mazancova J, Siroky P (2012) Theileria, Babesia, and Anaplasma detected by PCR in ruminant herds at Bie Province, Angola. Parasite 19:417-422. https://doi.org/10.1051/parasite/ 2012194417

Liu Z, Ma M, Wang Z, Wang J, Peng Y, Li Y, Guan G, Luo J, Yin H (2012) Molecular survey and genetic identification of Anaplasma species in goats from central and southern China. Appl Environ Microbiol 78:464 470. https://doi.org/10.1128/AEM.06848-11

Michelet L, Delannoy S, Devillers E, Umhang GÃ®, Aspan A, Juremalm M, Chirico J, van der Wal FJ, Sprong H, Boye Pihl TP, Klitgaard K, BÃ sker R, Fach P, Moutailler S (2014) High-throughput screening of tick-borne pathogens in Europe. Front Cell Infect Microbiol 4: 103. https://doi.org/10.3389/fcimb.2014.00103

Mushi EZ, Isa JFW, Sakia RM (1996) Monthly fluctuation of Ixodid tick infestation on indigenous goats in Botswana. Small Rumin Res 21: 277-279. https://doi.org/10.1016/0921-4488(95)00830-6

Ndung'u LW, Aguirre C, Rurangirwa FR, McElwain TF, McGuire TC, Knowles DP, Palmer GH (1995) Detection of Anaplasma ovis infection in goats by major surface protein 5 competitive inhibition enzyme-linked immunosorbent assay. J Clin Microbiol 33:675-679

Panin A (2000) A comparative economic analysis of smallholder cattle and small ruminant production systems in. Trop Anim Health Prod 32:189-196

Panin A, Mahabile M (1997) Profitability and household income contribution of small ruminants to small-scale farmers in Botswana. Small Rumin Res 25:9-15. https://doi.org/10.1016/S0921-4488(96) 00967-4

Ramabu SS, Kgwatalala PM, Nsoso SJ, Gasebonwe S, Kgosiesele E (2018) Anaplasma infection prevalence in beef and dairy cattle in the south east region of Botswana veterinary parasitology. Vet Parasitol Reg Stud Reports 12:4-8

Renneker S, Abdo J, Salih DEA, Karagenç T, Bilgiç H, Torina A, Oliva AG, Campos J, Kullmann B, Ahmed J, Seitzer U (2013) Can Anaplasma ovis in small ruminants be neglected any longer? Transbound Emerg Dis 60(Suppl 2):105-112. https://doi.org/10. 1111/tbed.12149

Rymaszewska A, Grenda S (2008) Bacteria of the genus Anaplasma characteristics of Anaplasma and their vectors: a review. Vet Med 53:573-584

Shompole S, Waghela SD, Rurangirwa FR, McGuire TC (1989) Cloned DNA probes identify Anaplasma ovis in goats and reveal a high prevalence of infection. J Clin Microbiol 27:2730-2735

World Bank (2016) Botswana overview. The World Bank. http://www. worldbank.org/en/country/botswana/overview. Accessed 30th November 2016

Publisher's note Springer Nature remains neutral with regard to jurisdictional claims in published maps and institutional affiliations. 